DOI: $10.29303 /$ jrpb.v8i1.160

ISSN 2301-8119, e-ISSN 2443-1354

Tersedia online di http://jrpb.unram.ac.id/

\title{
KAJIAN RASIO REFLUKS PADA ISOLASI BEBERAPA SENYAWA MINYAK NILAM (Pogostemon cablin Benth) DENGAN METODE DISTILASI FRAKSINASI
}

\author{
Study of Reflux Ratio on Isolation of Some Patchouli (Pogostemon cablin Benth) Oil \\ Compounds by Fractional Distillation Method
}

\section{Irene June Sidabutar*), Asri Widyasanti, Sarifah Nurjanah, Bambang Nurhadi, Tita Rialita, Elazmanawati Lembong}

Program Studi Teknik Pertanian, Universitas Padjadjaran

J1. Raya Bandung Sumedang Km.21, Jatinangor 4536, Indonesia

Email*): irenesidabutar28@gmail.com

Diterima: Desember 2019

Disetujui: Februari 2020

\begin{abstract}
Patchouli oil produced by farmers generally still has a low quality due to improper harvest handling and postharvest techniques. Several studies have been carried out to improve the quality of patchouli oil by using the fractional distillation method. Fractional distillation is the process of separating components based on boiling points of compounds. This study aims to determine the effect of reflux ratio on operating conditions and the optimal reflux ratio to obtain high purity compounds. The research method used was an experimental method with descriptive analysis. This research was conducted using three variables, i.e., reflux ratio of 20:1, 30:1 and 40:1 with twice repetition, and arranged to produce 5 fractions (cut) on each variable. The parameters measured include specific gravity, refractive index, process yield, residual mass, lost mass and total distillation time. The results showed that influence on the operating conditions where the greater the reflux ratio used, the time needed for fractional distillation was also longer. Optimal operating conditions are obtained at a reflux ratio of 20:1. The length of time and process yield are 10.9 hours and 93\%, respectively. Reflux ratio of 20:1 is considered the most efficient because of the shorter fractional time and is able to produce a high yield.
\end{abstract}

Keywords: fractional distillation, patchouli oil, reflux ratio

\begin{abstract}
ABSTRAK
Minyak nilam yang dihasilkan oleh petani umumnya masih memiliki kualitas yang rendah dikarenakan teknik penanganan panen dan pascapanen yang kurang tepat. Beberapa penelitian telah dilakukan untuk meningkatkan mutu minyak nilam dengan menggunakan metode distilasi fraksinasi. Distilasi fraksinasi merupakan proses pemisahan komponen berdasarkan titik didih senyawa. Penelitian ini bertujuan untuk mengetahui pengaruh rasio refluks terhadap kondisi proses distilasi fraksinasi. Metode penelitian yang digunakan adalah metode eksperimen dengan analisis deskriptif. Penelitian ini dilakukan dengan menggunakan tiga variabel, yaitu rasio refluks 20:1, 30:1 dan 40:1 dengan pengulangan sebanyak dua kali, serta diatur untuk
\end{abstract}


menghasilkan 5 fraksi (cut) pada masing variabel. Parameter yang diukur meliputi bobot jenis, indeks bias, rendemen proses, massa residu, massa hilang dan total lama waktu distilasi. Hasil penelitian menunjukkan perlakuan refluks memberikan pengaruh terhadap kondisi operasi dimana semakin besar rasio refluks yang digunakan maka waktu yang dibutuhkan untuk distilasi fraksinasi juga semakin lama. Kondisi operasi optimal diperoleh pada rasio refluks 20:1. Perolehan lama waktu dan rendemen proses secara berturut adalah 10,9 jam dan 93\%. Rasio refluks 20:1 dinilai lebih efisien karena waktu fraksinasi yang lebih singkat serta mampu menghasilkan rendemen yang tinggi.

Kata kunci: distilasi fraksinasi, minyak nilam, rasio refluks

\section{PENDAHULUAN}

\section{Latar Belakang}

Minyak nilam merupakan salah satu jenis minyak atsiri yang memiliki tingkat produksi yang tinggi dan menjadi komoditas ekspor non migas Indonesia yang mampu menghasilkan devisa negara. Indonesia menyuplai sekitar 90\% kebutuhan minyak nilam dunia (Rukmana, 2004). Minyak nilam dalam dunia perdagangan dikenal dengan nama patchouli oil merupakan bahan baku yang penting untuk industri wewangian dan kosmetika. Minyak nilam memiliki sifat daya fiksasi yang kuat terhadap bahan pewangi lain, sehingga dapat mengikat bau dan mencegah penguapan pada zat pewangi agar aroma dapat bertahan lebih lama (Mahanta, dkk., 2007).

Minyak nilam memiliki beberapa kandungan senyawa penelitian yang dilakukan oleh Aisyah, dkk., (2008) menghasilkan 15 komponen penyusun minyak nilam yang teridentifikasi melalui analisis Kromatografi Gas-Spektrometri Massa (GCMS). Menurut Nurjanah, dkk., (2017) terdapat 5 senyawa dominan pada minyak nilam yaitu yaitu patchouli alcohol, $\Delta$-guaiene, $\alpha$-guaiene, seychellene dan $\alpha$ patchoulene. Komponen dalam minyak nilam yang berfungsi sebagai zat fiksatif adalah patchouli alcohol yang juga merupakan komponen utama penentu mutu dan aroma dari minyak nilam. Peningkatan mutu minyak nilam dapat dilakukan dengan berbagai metode salah satunya adalah distilasi frakasinasi. Distilasi fraksinasi adalah pemisahan komponen senyawa menjadi fraksi berdasarkan perbedaan titik didihnya (Ramsden, 2012). Proses distilasi fraksinasi dipengaruhi oleh beberapa variabel seperti suhu, tekanan, kolom fraksinasi, dan rasio refluks. Penentuan rasio refluks disesuaikan agar dapat menghasilkan pemisahan campuran yang efektif dan efisien.

Rasio refluks didefinisikan sebagai rasio dari jumlah tetesan kondensat yang kembali ke dalam kolom dan labu didih dengan jumlah tetesan yang dikumpulkan sebagai distilat (Pavia, 2005). Rasio refluks yang terlalu kecil dapat menyebabkan terjadinya pemisahan komponen yang tidak tepat, sehingga akan menghasilkan fraksi yang belum murni karena masih memiliki kandungan komponen lain yang tidak diinginkan. Sedangkan rasio refluks yang terlalu besar akan menghasilkan pemisahan komponen yang berlangsung lambat dan tidak efisien, walaupun mampu menghasilkan kemurnian komponen yang tinggi (Gilbert dan Martin, 2010). Penelitian mengenai distilasi fraksinasi vakum minyak nilam telah banyak dilakukan. Namun, belum banyak ditemukan kondisi operasi yang paling optimal dalam proses pemisahan senyawa pada minyak nilam, khususnya yang mengkaji penggunaan rasio refluks.

Berdasarkan penelitian Nurjanah, dkk (2017) dilakukan distilasi fraksinasi yang ditentukan berdasarkan suhu komponen di dalam minyak nilam yaitu antara $280^{\circ} \mathrm{C}-$ $300^{\circ} \mathrm{C}$ yang dibentuk menjadi tiga fraksi yaitu fraksi $1\left(230^{\circ} \mathrm{C}-283^{\circ} \mathrm{C}\right)$, fraksi 2 $\left(283^{\circ} \mathrm{C}-290^{\circ} \mathrm{C}\right)$, dan fraksi $3\left(290^{\circ} \mathrm{C}-\right.$ $\left.300^{\circ} \mathrm{C}\right)$. Berdasarkan hasil pengujian GCMS (Gas Chromatography Mass Spectrometry) 
fraksi 1 masih terdapat senyawa yang berharga dan kandungan yang cukup tinggi, sehingga diperlukan proses pengisolasian senyawa - senyawa tersebut.

\section{Tujuan}

Tujuan dari penelitian ini adalah menganalisis pengaruh rasio refluks yang digunakan dalam pengisolasian senyawa dominan pada distilasi fraksinasi seperti pengaruh pada rendemen distilat, massa residu, massa hilang dan lama waktu proses distilasi, serta menganalisis pengaruh rasio refluks terhadap bobot jenis dan indeks biasnya. Selain itu, perlu dipertimbangkan pula rasio refluks terbaik untuk menghasilkan kondisi distilasi fraksinasi yang optimal.

\section{METODE PENELITIAN}

\section{Alat dan Bahan}

Bahan baku yang digunakan dalam penelitian ini adalah minyak nilam fraksi 1 $\left(230^{\circ} \mathrm{C}-283^{\circ} \mathrm{C}\right)$, hasil destilasi fraksinasi pada penelitian dari Nurjanah, dkk (2017) mengenai rekayasa produksi minyak nilam dilakukan distilasi fraksinasi vakum sebagai upaya untuk meningkatkan kadar patchouli alcohol. Sedangkan bahan kimia yang digunakan untuk pengujian karakteristik minyak nilam yaitu etanol $90 \%$ untuk membersihkan mesin distilasi.

Alat yang digunakan pada penelitian ini yaitu mesin distilasi fraksinasi $B / R$ Instrument - Spinning Band Distillation System Model 36-100 yang terintegrasi dengan computer melalui program kontrol BR M690, gelas ukur $10 \mathrm{~mL}$ dan $100 \mathrm{~mL}$, timbangan (ketelitian 0,01), dan botol kaca $60 \mathrm{~mL}$. Sedangkan alat untuk analisis karakteristik yaitu piknometer pada analisis bobot jenis dan refraktometer ABBE pada analisis indeks bias.

\section{Metode}

Metode yang digunakan pada penelitian ini adalah deskriptif. Proses distilasi fraksinasi dilakukan dengan pemberian perlakuan refluks 20:1, 30:1, dan
40:1, masing masing perlakuan refluks dilakukan sebanyak dua kali ulangan.

\section{Tahapan Penelitian}

Proses destilasi fraksinasi dilakukan dengan menggunakan $B / R$ Instrument Spinning Band Distillation System Model 36-100. Sampel yang digunakan pada setiap proses destilasi adalah $100 \mathrm{ml}$. Pada program, distilasi frakasinasi diatur untuk menghasilkan 5 fraksi (cut) pada masingmasing variabel rasio refluks, sehingga pada program terdapat 5 proses pengumpulan destilat fraksi 1 hingga fraksi 5 berturutturut, yaitu seychellene, $\alpha$-patchoulene, $\Delta$ guaiene, $\alpha$-guaiene, dan patchouli alcohol. Proses penentuan suhu fraksi ini didasarkan pada titik didih senyawa-senyawa yang dominan pada minyak nilam yang diharapkan hasil dari tiap fraksi berturutturut, yaitu seychellene, $\alpha$-patchoulene, $\Delta$ guaiene, $\alpha$-guaiene, dan patchouli alcohol. Kondisi operasi proses destilasi fraksinasi disajikan pada Tabel 1 untuk ketiga variabel refluks.

Tabel 1. Kondisi operasi proses distilasi fraksinasi

\begin{tabular}{lcc}
\hline Variabel Proses & $\begin{array}{c}\text { Nilai yang } \\
\text { digunakan }\end{array}$ & Satuan \\
\hline Pressure & 10 & $\mathrm{mmHg}$ \\
Column Length & 90 & $\mathrm{~cm}$ \\
Initial Heat & 25 & $\%$ \\
Equibration & 15 & Menit \\
Time & 300 & ${ }^{\circ} \mathrm{C}$ \\
Max Pot Temp & $249-254$ & ${ }^{\circ} \mathrm{C}$ \\
Fraksi 1 & $254-259$ & ${ }^{\circ} \mathrm{C}$ \\
Fraksi 2 & $259-264$ & ${ }^{\circ} \mathrm{C}$ \\
Fraksi 3 & $264-269$ & ${ }^{\circ} \mathrm{C}$ \\
Fraksi 4 & $269-274$ & ${ }^{\circ} \mathrm{C}$ \\
Fraksi 5 & 27 & ${ }^{\circ}$ \\
Heat Rate & 35 & ${ }^{\circ} \mathrm{C}$ \\
Condenser & & \\
Temp & & \\
\hline
\end{tabular}

\section{Analisis Karakteristik Fisiko-Kimia Minyak Nilam}

Minyak nilam awal serta minyak nilam hasil distilasi fraksinasi yang dihasilkan dianalisis karakteristiknya (bobot jenis dan indeks bias). Proses analisis 
karakteristik minyak nilam mengacu pada nilai standar masing senyawa yang dituju pada tiap fraksinya. Standar bobot jenis untuk senyawa seychellene, $\alpha$-patchoulene, $\Delta$-guaiene, dan patchouli alcohol belum ada, sehingga standar nilai bobot jenis yang diperoleh dibandingkan dengan bobot jenis pada SNI minyak nilam (06-2385-2006), serta untuk $\alpha$-guaiene memiliki nilai bobot jenis sebesar 0,8970-0,9030 (The Good Scent Company, 2018). Standar indeks bias untuk senyawa seychellene, $\alpha$-patchoulene belum memiliki standar sehingga indeks bias yang diperoleh dibandingkan dengan SNI minyak nilam, untuk senyawa $\Delta$ guaiene memiliki standar indeks bias sebesai 1,5050 (Chemical Book, 2006) serta $\alpha$-guaiene dan patchouli alcohol berturutturut nilai standar indeks bias sebesar 1,4930-1,4990 dan 1,5245 (The Good Scent Company, 2018).

\section{HASIL DAN PEMBAHASAN}

\section{Hasil Distilasi Fraksinasi Minyak Nilam}

Proses distilasi fraksinasi yang telah dilakukan pada tiap masing-masing perlakuannya diperoleh hasil fraksi yang berbeda-beda. Distilasi fraksinasi pada perlakuan rasio refluks 20:1 untuk ulangan 1 mendapatkan 5 fraksi sedangkan untuk ulangan 2 hanya terdapat 4 fraksi dari 5 fraksi yang diharapkan. Pada perlakuan rasio refluks 30:1 di ulangan 1 diperoleh 4 fraksi dari 5 fraksi yang diharapkan dan untuk ulangan 2 diperoleh 5 fraksi. Adapun pada perlakuan rasio refluks 40:1 hanya memperoleh 4 fraksi pada tiap ulangannya.

\section{Rendemen Hasil Distilasi Fraksinasi}

Rendemen yang dihasilkan dari proses distilasi fraksinasi terbagi dua, yaitu rendemen parsial dan rendemen total proses. Rendemen parsial adalah rendemen yang diperoleh pada tiap fraksi. Rendemen parsial masing fraksi pada tiap perlakuannya disajikan pada Gambar 1.

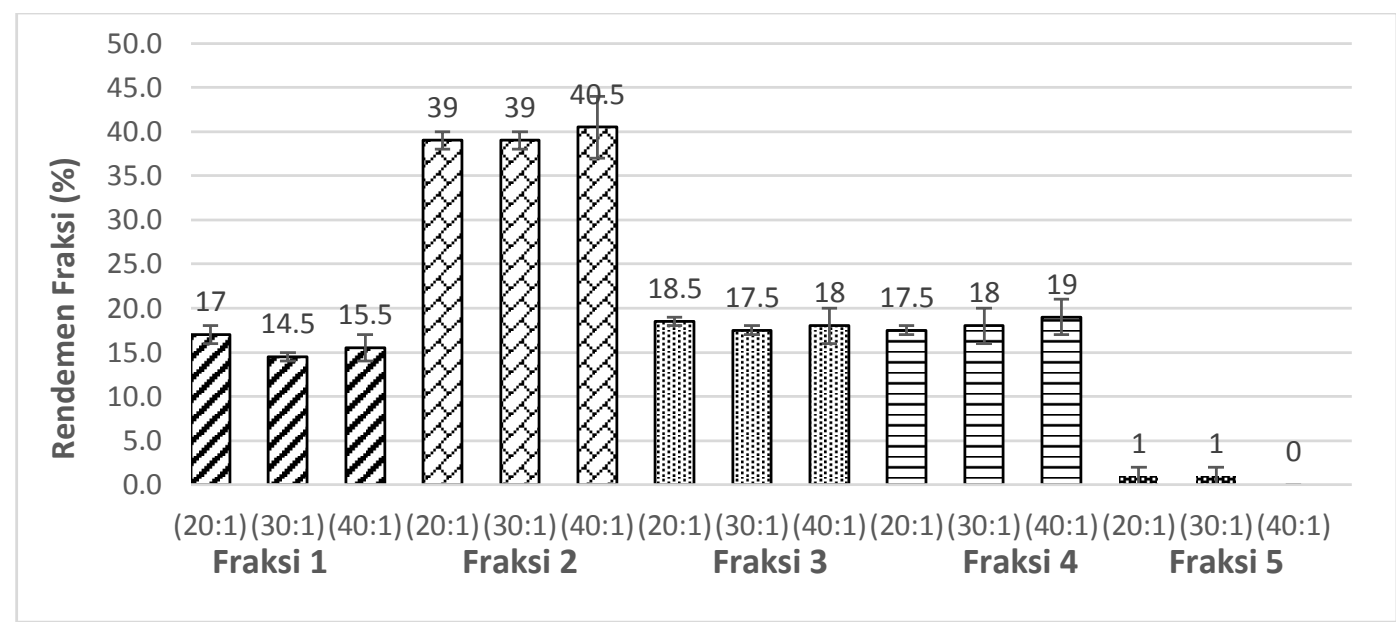

Gambar 1. Rendemen Parsial Proses Distilasi Fraksinasi Minyak Nila

Hasil rendemen parsial yang diperoleh fraksi $2\left(254^{\circ} \mathrm{C}-259^{\circ} \mathrm{C}\right)$ lebih banyak dibandingkan fraksi lainnya, sekitar 39\%. Sedangkan rendemen parsial terkecil terdapat pada fraksi $5\left(269^{\circ} \mathrm{C}-274^{\circ} \mathrm{C}\right)$, sekitar $1 \%$. Rendemen total proses dari perlakuan perlakuan 20:1, 30:1, dan 40:1 berturut-turut adalah $93 \%, 90 \%$, dan $94 \%$. Hasil rendemen yang diperoleh pada rendemen parsial dan rendemen total menunjukkan bahwa pemberian variasi refluks tidak memberikan pengaruh yang signifikan dikarenakan refluks sebagai variabel bebas yang tidak mempengaruhi rendemen yang dihasilkan melainkan mempengaruhi kemurnian komponennya. Variabel yang mempengaruhi rendemen diantaranya tekanan dan suhu yang digunakan pada 
proses distilasi. Namun, pada penelitian ini digunakan tekanan dan suhu distilasi yang sama sehingga rendemen yang dihasilkan tidak berbeda jauh. Hal senada juga diperoleh dari penelitian Amrullah, dkk., (2017), bahwa rasio refluks (20:1) sudah cukup baik menghasilkan mutu minyak nilam.

\section{Lama waktu Distilasi Fraksinasi}

Rasio refluks didefinisikan sebagai rasio dari jumlah tetesan kondesat yang kembali ke dalam kolom fraksinasi dan labu didih dengan jumlah tetesan kondensat yang dikumpulkan sebagai distilat per unit waktu yang diatur dalam katup refluks. Sebagai contoh pada sebuah proses distilasi fraksinasi digunakan rasio refluks 20:1 didefinisikan sebagai sejumlah kondensat yang kembali ke kolom fraksinasi dan labu didih selama 20 detik katup tertutup dengan sejumlah kondesat yang masuk sebagai distilat selama 1 detik katup terbuka.

Waktu total distilasi fraksinasi sangat dipengaruhi oleh rasio refluks yang digunakan, hal ini dikarenakan rasio refluks mempengaruhi lamanya proses pengumpulan distilat pada tiap fraksi. Total waktu yang dibutuhkan perlakuan 20:1, 30:1, dan 40:1 untuk menyelesaikan proses distilasi fraksinasi berturut-turut adalah 10,9 jam, 12,9 jam dan 16,63 jam untuk jumlah sampel sebanyak $100 \mathrm{ml}$. Hasil pengukuran lama waktu proses distilasi fraksinasi yang didapatkan sesuai dengan penelitian Gilbert dan Martin (2010) dinyatakan semakin kecil rasio refluks yang digunakan, maka semakin sedikit pula lama waktu atau semakin cepat lama waktu yang dibutuhkan proses distilasi fraksinasi.

\section{Massa Residu dan Massa Hilang}

Pada akhir proses distilasi fraksinasi juga dihasilkan residu, yaitu bahan yang tertinggal dalam labu didih yang tidak dapat terdistilasi lagi. Massa residu terbesar ke terkecil secara berturut-turut didapatkan pada perlakuan refluks 20:1 sebesar $6,25 \%$, refluks 30:1 sebesar 5,21\% dan refluks 40:1 sebesar 3,65\%. Residu yang dihasilkan dari proses distilasi fraksinasi minyak nilam memiliki karakteristik berwarna cokelat kehitaman dengan tekstur yang kental pada suhu tinggi dan berubah menjadi keras ketika dibiarkan di suhu ruang. Oleh karena itu, residu segera dikeluarkan dari labu didih dengan melarutkannya dengan pelarut organik seperti aseton. Penampakan residu dari proses distilasi fraksinasi disajikan pada Gambar 2.

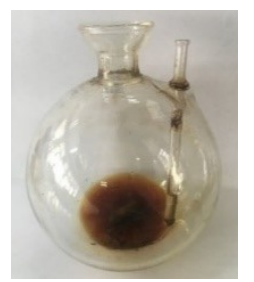

Gambar 2. Penampakan Residu

Massa loss atau massa yang hilang selama proses distilasi fraksinasi berlangsung juga diukur dalam penelitian ini. Massa yang hilang dapat disebabkan oleh minyak yang tertinggal atau menempel pada komponen-komponen alat distilasi fraksinasi. Massa hilang terbesar ke terkecil berturut-turut ditunjukkan pada proses refluks 30:1 sebesar 4,79\%, refluks 40:1 sebesar 2,35\% dan refluks 20:1 sebesar $0,75 \%$. Massa hilang perlakuan refluks 30:1 lebih besar dibandingkan dua perlakuan lainnya.

\section{Karakteristik Minyak Nilam}

Hasil pengujian karakteristik minyak nilam bahan awal disajikan pada Tabel 2 .

Tabel 2. Karakteristik Minyak Nilam Bahan Awal

\begin{tabular}{lll}
\hline Karakteristik & SNI 06-2385-2006 & $\begin{array}{l}\text { Nilam } \\
\text { Awal }\end{array}$ \\
\hline Bobot Jenis & $0,950-0,975$ & 0,956 \\
Indeks Bias & $1,507-1,515$ & 1,504 \\
\hline
\end{tabular}

Hasil pengujian bobot jenis diperoleh bahan awal minyak nilam sesuai dengan SNI sedangkan indeks biasnya masih berada dibawah standar. Setelah proses distilasi fraksinasi, dilakukan pengujian bobot jenis dan indeks bias pada masing-masing fraksi yang diperoleh. 


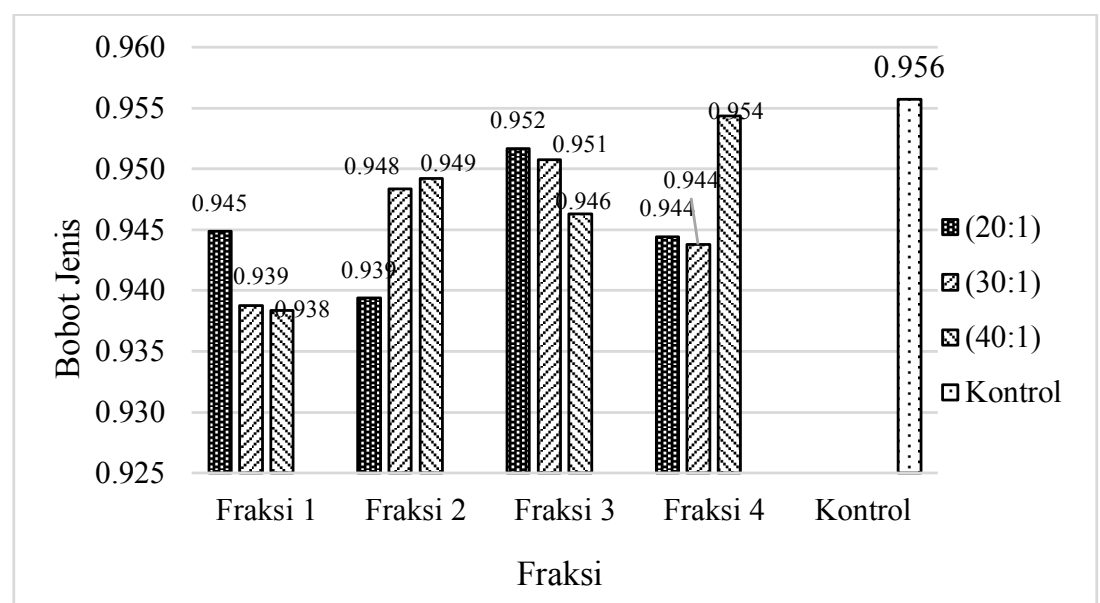

Gambar 3. Bobot Jenis Minyak Nilam Awal dan Hasil Distilasi Fraksinasi

\section{a. Bobot Jenis}

Bobot jenis minyak nilam hasil distilasi fraksinasi yang diperoleh dalam penelitian ini disajikan pada Gambar 3. Hasil pengukuran menunjukkan bahwa terjadi penurunan bobot jenis setelah dilakukan distilasi fraksinasi; dapat dilihat nilai bobot jenis pada tiap fraksi tiap perlakuan setelah distilasi nilai indeks bias lebih kecil dibandingkan dengan minyak nilam awal. Adapun hasil bobot jenis yang diperoleh pada masing fraksi dibandingkan dengan SNI dan standar masing senyawa. Senyawa seychellene, $\alpha$-patchoulene, dan $\Delta$-guaiene dibandingkan dengan bobot jenis SNI. Bobot jenis yang sesuai dengan SNI hanya terdapat pada senyawa $\triangle$-guaiene dengan rasio refluks
20:1 dan 30:1. Adapun senyawa $\alpha$-guaiene untuk tiap perlakuannya nilai bobot jenis tidak sesuai dengan standar senyawa $\alpha$ guaiene. Rendahnya nilai bobot jenis diduga karena pada fraksi terkandung lebih banyak fraksi ringan seperti $\alpha$-patchoulene, seychellene, $\Delta$-guaiene, dan $\alpha$-guaiene yang memiliki berat molekul rendah dan mudah menguap (Aisyah dan Anwar, 2012).

\section{b. Indeks Bias}

Nilai indeks bias minyak ditentukan oleh banyaknya cahaya yang melewati media kurang padat ke media lebih padat, maka sinar akan membelok atau membias dari garis normal. Nilai indeks bias yang diperoleh pada masing fraksi disajikan pada Gambar 4.

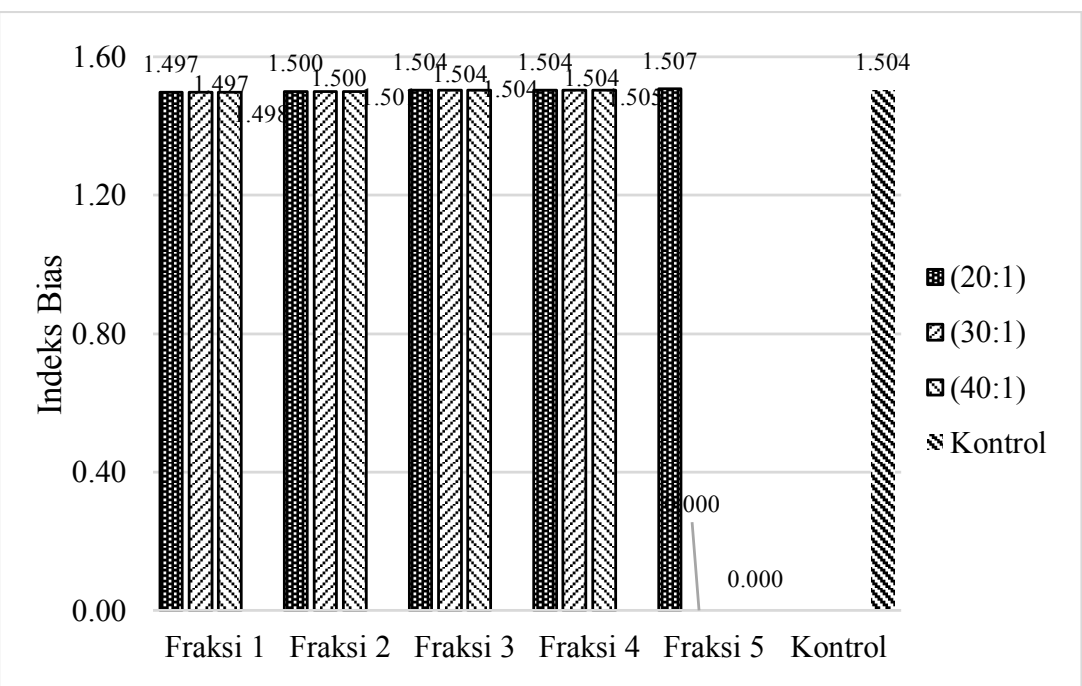

Gambar 4. Indeks Bias Minyak Nilam Awal dan Hasil Distilasi Fraksinasi 
Senyawa hasil distilat indeks bias yang diperoleh dibandingkan dengan beberapa literatur indeks bias masing senyawa, namun untuk senyawa seychellene dan $\alpha$ patchoulene belum memiliki standar sehingga nilai bobot jenis dibandingkan dengan bobot jenis pada SNI. Senyawa 4 guaiene memiliki nilai indeks bias sebesar 1,5050 (Chemical Book, 2006). Adapun pada senyawa $\alpha$-guaiene dan patchouli alcohol berturut-turut sebesar 1,4930 - 1,4990 dan 1,5245 (The Good Scent Company, 2018).

Hasil pengukuran indeks bias pada hasil distilasi fraksinasi menunjukkan pemberian perlakuan rasio refluks tidak memberikan pengaruh yang signifikan pada nilai indeks bias. Hasil pengukuran menunjukkan bahwa semakin tinggi fraksi hasil distilasi, nilai indeks bias yang diperoleh pula semakin tinggi. Hasil pengujian indeks bias untuk senyawa seychellene, $\alpha$-patchoulene, $\Delta$-guaiene, $\alpha$ guaiene, dan patchouli alcohol masih belum sesuai dengan SNI dan standar masing senyawa. Sama halnya dengan bobot jenis, komponen penyusun minyak nilam mempengaruhi nilai indeks biasnya. Semakin banyak komponen berantai panjang seperti sesquiterpen atau komponen bergugus oksigen, maka kerapatan medium minyak nilam akan bertambah sehingga cahaya yang datang akan lebih sukar untuk dibiaskan, akibatnya nilai indeks bias minyak nilam lebih besar. Berdasarkan hasil pengukuran rendahnya nilai indeks bias disebabkan sedikitnya komponen berantai panjang pada fraksi. Rendahnya komponen berantai panjang menyebabkan kerapatan medium menjadi rendah sehingga cahaya yang datang lebih banyak dibiaskan dan nilai indeks bias menjadi lebih kecil (Rosi,2016).

\section{KESIMPULAN DAN SARAN}

\section{Kesimpulan}

Perlakuan rasio refluks pada proses distilasi fraksinasi tidak berpengaruh secara signifikan terhadap kemurnian senyawa dimana hasil nilai indeks bias yang diperoleh cenderung tidak berbeda. Namun, rasio refluks berpengaruh terhadap kondisi operasi dimana semakin besar rasio refluks yang digunakan, waktu yang dibutuhkan untuk proses distilasi fraksinasi semakin lama. Kondisi operasi rasio refluks 20:1 dinilai lebih efisien karena waktu refluks yang lebih singkat, sehingga akan menghemat waktu proses serta mampu menghasilkan rendemen yang tinggi, yaitu sebesar $93 \%$.

\section{Saran}

Hasil distilasi fraksinasi yang diperoleh sebaiknya diuji kandungan senyawa yang terdapat pada tiap fraksinya dengan menggunakan GCMS sehingga dapat diketahui kadar kandungan seychellene, $\alpha$ patchoulene, $\Delta$-guaiene, $\alpha$-guaiene, dan patchouli alcohol yang diperoleh pada tiap perlakuan.

\section{UCAPAN TERIMA KASIH}

Penulis mengucapkan terima kasih kepada Laboratorium Pasca Panen dan Teknologi Proses serta Laboratorium Keteknikan Pangan Fakultas Teknologi Industri Pertanian, Universitas Padjadjaran yang menyediakan fasilitas untuk melakukan penelitian ini. Semoga penelitian ini dapat bermanfaat bagi pembaca.

\section{DAFTAR REFERENSI}

Aisyah, Y., \& Anwar, S.H. (2012). Physicochemical properties of patchouli oils (Pogostemon cablin) separated by fractional distillation method. Proceedings of The Annual International Conference, Syiah Kuala University - Life Sciences \& Engineering, 2(2), 355-359.

Aisyah, Y., Hastuti, P., Sastrohamidjojo, H., \& Hidayat, C. (2008). Komposisi kimia dan sifat antibakteri minyak nilam (Pogostemon cablin). Majalah Farmasi Indonesia, 19(3), 151-156.

Amrullah, R., Nurjanah, S., Widyasanti, A., \& Muhaemin, M. (2017). Kajian 
Pengaruh Rasio Refluks Terhadap Karakteristik Minyak Nilam Hasil Distilasi Fraksinasi. Jurnal Teknotan, 11(2), 77-88.

Chemical Book. (2006). Refractive Index $\alpha-$ Bulnesene. Diakses 19 Oktober 2019 dari http://chemicalbook.com.

Gilbert, J.C., \& Martin, S.F. (2010). Experimental organic chemistry: a miniscale and microscale approach, 5th edition. USA: Cengage Learning.

Mahanta, J.J., Chutia, M., \& Sarma, T.C., (2007). Study on Weed Flora and Their Influence on Patchouli (Pogostemon cablin Benth.) Oil and Patchoulol. Journal of Plant Sciences, 2(1), 96101.

Nurjanah, S., Muhaemin, M., \& Widyasanti, A. (2017). Laporan Akhir Tahun: Rekayasa Produksia Nilam Kristal Guna Meningkatkan Ekspor Komoditi Hilir Minyak Atsiri. Jatinangor: Universitas Padjadjaran.
Pavia, D.L. (2005). Introduction to Organic Laboratory Techniques: a Small Scale Approach, Second edition. USA: Brooks/Cole, Thomson Learning Inc.

Ramsden, E.N. (2012). Key Science Chemistry, $3^{\text {rd }}$ Edition. United Kingdom: Nelson Thomes.

Rosi, D.M. (2016). Uji Aktivitas AntiBakteri pada Minyak Nilam Hasil Distilasi Fraksinasi terhadap Bakteri Gram Positif (propionobacterium acnes dan Stahpylococcus aureus) dan Bakteri Gram Negatif (Pseudomonas aeriginosa dan Enterobacter aerogenes). Skripsi. Fakultas Teknologi Industri Pertanian. Universitas Padjadjaran.

Rukmana, R. (2004). Nilam: prospek agribisnis dan teknik budi daya. Yogyakarta: Kanisius.

The Good Scent Company. (2018). $\alpha-$ guaiene dan Patchouli Alcohol. Diakses 19 Oktober 2019 dari http://thegodscentcompany.com. 